\title{
Efeito Residual do pó de rocha basáltica nos atributos químicos e microbiológicos do solo e no estado nutricional da cultura da soja
}

\author{
Residual effect of basaltic rock powder on the chemical and microbiological attributes of the soil \\ and on the nutritional status of the soybean crop
}

Efecto residual del polvo de roca basáltica sobre los atributos químicos y microbiológicos del suelo y sobre el estado nutricional del cultivo de soja

\section{Resumo}

A agricultura brasileira encontra-se, em grande parte, dependente de fertilizantes químicos solúveis. Contudo, existem alternativas como o pó de rocha, um resíduo da mineração, que possui poder residual de liberação de nutrientes. $\mathrm{O}$ objetivo deste trabalho foi avaliar o efeito residual de quarto ano da rochagem nos atributos químicos, microbiológicos e no estado nutricional da cultura da soja. O experimento foi realizado na Fazenda Experimental da UFGD, em Dourados (MS), em um Latossolo Vermelho Distroférrico. O delineamento experimental foi em parcelas subdivididas casualizadas por bloco, com quatro repetições. As parcelas continham as doses $(0 ; 2,5 ; 5,0 ; 7,5$ e 10 Mg.ha-1 ${ }^{-1}$ e as subparcelas a adubação química (com e sem adubação). Após a colheita, coletou-se amostras de solo de 0-10 e 10-20 cm para análise química. Para a análise microbiológica, coletou-se no florescimento da soja amostras de solo a $10 \mathrm{~cm}$ para avaliar o $\mathrm{qCO}_{2}$ e o qMIC. Para o estado nutricional da cultura, coletou-se o terceiro trifólio com pecíolo no estádio R2. Os dados foram submetidos à análise de variância, as médias comparadas pelo Teste $\mathrm{t}$ de Student a 5\% e para as doses (significativas) houve análise de regressão. O pó de rocha influenciou os teores de Fe, de 0-10 cm, e o pH $\mathrm{H}_{2} \mathrm{O}$ e $\mathrm{Mn}$ a 10-20 cm. Na análise foliar, houve interação entre doses de basalto e adubação para $\mathrm{P}$ e efeito isolado das doses para $\mathrm{K}, \mathrm{Ca}$ e $\mathrm{Mn}$. O efeito residual da rochagem basáltica pode afetar os atributos químicos do solo e nutrição da cultura.

Palavras-chave: Pó de Basalto; Remineralizador de solo; Resíduo de mineração.

\begin{abstract}
Brazilian agriculture is largely dependent on soluble chemical fertilizers. However, there are alternatives such as rock dust, a waste from mining, which has residual power to release nutrients. The objective of this work was to evaluate the fourth-year residual effect of stonemeal on chemical, microbiological and nutritional status of soybean crop. The experiment was carried out at the Experimental Farm of UFGD, in Dourados (MS), in a Dystroferric Red Latosol. The experimental design was in randomized split plots per block, with four replications. The plots contained the doses $(0$, 2.5, 5.0, 7.5 and $10 \mathrm{Mg}$.ha-1) and the subplots chemical fertilization (with and without fertilization). After harvesting, soil samples of 0-10 and 10-20 cm were collected for chemical analysis. For microbiological analysis, soil samples were collected at $10 \mathrm{~cm}$ from soybean flowering to evaluate qCO2 and qMIC. For the nutritional status of the crop, the third trefoil with petiole at stage R2 was collected. Data were subjected to analysis of variance, means compared
\end{abstract}


by Student's t test at 5\% and for doses (significant) there was regression analysis. The rock powder influenced the Fe contents, from $0-10 \mathrm{~cm}$, and the $\mathrm{pH} \mathrm{H} 2 \mathrm{O}$ and $\mathrm{Mn}$ at $10-20 \mathrm{~cm}$. In the leaf analysis, there was an interaction between doses of basalt and fertilization for $\mathrm{P}$ and isolated effect of doses for $\mathrm{K}, \mathrm{Ca}$ and $\mathrm{Mn}$. The residual effect of basaltic rockstone can affect soil chemical attributes and crop nutrition.

Keywords: Basalt powder; Soil remineralizer; Mining waste.

\section{Resumen}

La agricultura brasileña depende en gran medida de los fertilizantes químicos solubles. Sin embargo, existen alternativas como el polvo de roca, un residuo de la minería, que tiene un poder residual para liberar nutrientes. El objetivo de este trabajo fue evaluar el efecto residual del cuarto año de la harina de piedra sobre el estado químico, microbiológico y nutricional del cultivo de soja. El experimento se llevó a cabo en la Granja Experimental de UFGD, en Dourados (MS), en un Latosol Rojo Distroférrico. El diseño experimental fue en parcelas divididas al azar por bloque, con cuatro repeticiones. Las parcelas contenían las dosis (0, 2.5, 5.0, 7.5 y $10 \mathrm{Mg}$.ha-1) y las subparcelas fertilización química (con y sin fertilización). Después de la cosecha, se recolectaron muestras de suelo de 0-10 y 10$20 \mathrm{~cm}$ para análisis químico. Para el análisis microbiológico, se recolectaron muestras de suelo a $10 \mathrm{~cm}$ de la floración de la soja para evaluar qCO2 y qMIC. Para el estado nutricional del cultivo se recogió el tercer trébol con pecíolo en la etapa R2. Los datos se sometieron a análisis de varianza, las medias se compararon mediante la prueba t de Student al 5\% y para las dosis (significativas) se realizó un análisis de regresión. El polvo de roca influyó en el contenido de $\mathrm{Fe}$, de 0-10 cm, y el pH H2O y Mn a 10-20 cm. En el análisis foliar, hubo interacción entre dosis de basalto y fertilización para P y efecto aislado de dosis para K, Ca y Mn. El efecto residual de la roca basáltica puede afectar los atributos químicos del suelo y la nutrición del cultivo.

Palabras clave: Polvo de basalto; Remineralizador de suelos; Residuos mineros.

\section{Introdução}

A agricultura brasileira encontra-se, em grande parte, dependente de fertilizantes químicos solúveis, os quais representam um dos maiores custos de produção. Isto ocorre devido a dependência do Brasil em importar dos EUA, Marrocos, Canadá e Rússia tal insumo, já que tais países possuem as principais jazidas minerais, fontes dos formulados NPK, considerados a base para a produção agrícola vigente (Theodoro et al., 2013).

A aplicação excessiva de tais fertilizantes químicos solúveis pode gerar problemas ambientais, pois uma vez que atingem águas superficiais e subterrâneas causam eutrofização devido ao aumento de nutrientes ricos em P e N, o que gera proliferação de algas e redução do teor de oxigênio, afetando os organismos presentes no ambiente (Nunes, 2012). Além disso, alguns fertilizantes solúveis são facilmente lixiviados, criando dependência de aquisição deste produto por parte do produtor, a cada novo ciclo de plantio, e do solo em necessitar dos nutrientes disponibilizados pelos adubos químicos (Brito et al. 2019).

Sendo assim, existem outras alternativas como o uso de pó de rocha na agricultura. O pó de rocha, ou remineralizador de solo, é definido como "material de origem mineral que passou apenas pela redução e classificação de tamanho por processos mecânicos e que altere os índices de fertilidade do solo por meio da adição de macro e micronutrientes para as plantas, bem como promova a melhoria das propriedades físicas ou físico-químicas ou da atividade biológica do solo" (Brasil, 2013). Portanto, o pó de rocha, um resíduo da britagem e corte de rochas, pode ser reutilizado no setor agrícola, somando-se mais uma vantagem no uso deste recurso: a sustentabilidade.

Neste contexto, Theodoro e Leonardos (2011) esclarecem em Rochagem: uma questão de soberania nacional, a respeito do uso de pó de rocha como adubação inteligente e de baixa dissolução, pois as raízes das plantas absorvem os elementos liberados a medida que necessitam. Assim, este insumo se comporta como um banco de nutrientes ao adicionar ao solo quantidades que foram perdidas ao longo dos anos por intemperismo, muito comum nos solos tropicais, ou por processos antrópicos. Os autores concluem que, além de benefícios como maior retenção de água pelas argilas em solos adubados com pó de rocha, o poder residual pode se estender por quatro a cinco anos seguidos, devido ao efeito de liberação lenta dos nutrientes.

O Brasil apresenta rochas com potencial de serem remineralizadores de solo, por exemplo o basalto (rocha ígnea vulcânica). Segundo Theodoro e Leonardos (2011), as rochas vulcânicas são as que têm apresentado melhores resultados, visto que, são compostas por minerais formados a partir de magmas mais segregados quimicamente e com baixo teor de sílica, ou 
seja, ricas em silicatos de ferro e magnésio.

Apesar disto, Theodoro (2000) relata sobre o custo de aquisição do pó de rocha, no qual o primeiro processo, a mineração, equivale-se ao custo de exploração de rochas fosfáticas utilizadas como matéria prima dos fertilizantes químicos. Porém, para o pó de rocha, não há a necessidade de gastos com processos de concentração e ataque químico como há para os fertilizantes solúveis. Rochas consideradas mais "duras", como o basalto, precisam passar pela moagem, sendo esta a segunda etapa do processo. Por fim, a fase de transporte até o agricultor, a mais custosa.

Portanto, o presente trabalho objetivou estudar o efeito residual da aplicação do pó de basalto, efetuada em 2017, nos atributos químicos e microbiológicos do solo, durante o cultivo da soja na safra de 2020, a fim de verificar o potencial deste resíduo da mineração na agricultura, para constatar sua eficiência, sustentabilidade e economia diante os fertilizantes químicos solúveis.

\section{Metodologia}

O experimento foi realizado na Fazenda Experimental de Ciências Agrárias da Universidade Federal da Grande

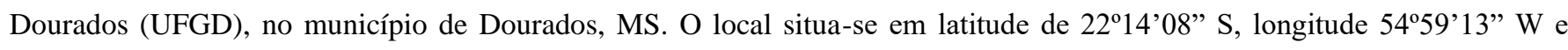
altitude de 434m, sendo o solo Latossolo Vermelho Distroférrico. O pó de basalto utilizado foi coletado na Mineradora Tozzi Junqueira Ltda-ME, em Itaporã, MS. Foi utilizado material residual fino resultante da operação de britagem. O pó de basalto foi aplicado manualmente, no ano de 2017, a lanço, sem incorporação, 30 dias antes da semeadura da soja. A granulometria estava de acordo com as normas da ABNT para classificação de corretivos e fertilizantes, sendo que $100 \%$ do produto passou em peneira de malha $0,84 \mathrm{~mm}$ e $50 \%$ em peneira de malha $0,3 \mathrm{~mm}$. O valor de $\mathrm{pH}$ era de 9,7 e a composição química total da rocha basáltica era de $\mathrm{SiO}_{2}: 51,4 \%$; $\mathrm{CaO}: 8,32 \%$; $\mathrm{MgO}: 3,58 \% ; \mathrm{K}_{2} \mathrm{O}: 3,42 \%$; $\mathrm{Zn:} 56,5 \mathrm{mgkg}^{-1}$; $\mathrm{Cu}: 182 \mathrm{mgkg}^{-1}$; $\mathrm{Ni}^{3} 3,77 \mathrm{mgkg}^{-}$ ${ }^{1}$; B: $107 \mathrm{mgkg}^{-1}$; Cl: $798 \mathrm{mgkg}^{-1}$; Co: 9,65 mgkg-1 ; Fe: $22.000 \mathrm{mgkg}^{-1}$; Mn: $394 \mathrm{mgkg}^{-1}$. Os elementos Cd, As, Pb, Hg e Mo se encontravam abaixo da faixa de quantificação. Os elementos macro e micro foram determinados por espectrometria de emissão, ICP.

O delineamento experimental adotado foi parcelas subdivididas casualizadas por bloco, com quatro repetições. A parcela foi constituída pelas doses de pó de basalto $(0 ; 2,5 ; 5,0 ; 7,5$ e $10 \mathrm{Mg}$ ha-1) e nas subparcelas a adubação química (com e sem adubação). Cada unidade experimental (parcela) era constituída por oito linhas de 5 metros, espaçadas em 0,45 m, perfazendo uma área total de $18 \mathrm{~m}^{2}$. A semeadura da soja ocorreu em novembro de 2019. A adubação química complementar foi realizada na safra anterior, de 2018/2019, com $200 \mathrm{kgha}^{-1}$ de NPK 0-20-20. Após a colheita da cultura, coletou-se amostras de solo nas profundidades de 0-10 e 10-20 cm para posterior análise química, englobando $\mathrm{pH}$ em água, $\mathrm{pH} \mathrm{CaCl}_{2}, \mathrm{Matéria}$ Orgânica, Ca, Mg, K, P Melich ${ }^{-1}$, Al, H+Al, SB, V\%, CTC total, Cu, Fe, Mn e Zn.

Para a análise microbiológica do solo, coletou-se no período de florescimento da soja (entre o estádio R1 e R2) amostras de solo na profundidade de $10 \mathrm{~cm}$, retirando-se da superfície do solo fragmentos vegetais. Estas foram armazenadas em câmara fria a $4^{\circ} \mathrm{C}$. Posteriormente, peneirou-se em malha de $2 \mathrm{~mm}$ e pesou-se $200 \mathrm{~g}$. O procedimento para análise de CBMS (carbono da biomassa microbiana do solo) foi de acordo com a metodologia original de Vance et al. (1987). A respiração basal (C-CO2) foi obtida pelo método de fumigação-incubação proposto por Jenkinson \& Powlson (1976). Após estes procedimentos, obtiveram-se o quociente metabólico $\left(\mathrm{qCO}_{2}\right)$ pela relação C- $\mathrm{CO}_{2} / \mathrm{C}-\mathrm{BMS}$ e o quociente microbiano (qMIC) pela equação CBMS/C orgânico total x 100 (Anderson \& Domsch, 1990).

Para se avaliar o estado nutricional das plantas, coletou-se o terceiro trifólio com pecíolo, do ápice para a base na haste principal, em 10 plantas por parcela, no estádio de desenvolvimento R2 (Costa \& Marquezan, 1982), as quais foram secas em estufa a $65^{\circ} \mathrm{C}$ e trituradas. Posteriormente, os teores de N, P, K, Ca, Mg, S, B, Cu, Fe, Mn e Zn, foram determinados conforme métodos descritos por Malavolta et al. (1997) 
Os resultados obtidos, em cada variável analisada, foram submetidos à análise de variância, e as médias dos tratamentos comparadas pelo Teste t de Student a 5\%, utilizando o programa estatístico Sisvar. Os dados das doses de pó de rocha (significativos) foram submetidos também a análise de regressão. Os modelos para ajustes das equações foram escolhidos com base no coeficiente de determinação e na sua significância $(\mathrm{p}<0,10)$.

\section{Resultados e Discussão}

Com relação aos atributos químicos do solo, na camada de 0-10 cm, a adubação química foi significativa para as variáveis $\mathrm{P}, \mathrm{Al}, \mathrm{Cu}$ e Fe (Tabela 1) e o efeito residual do pó de basalto foi significativo para a variável Fe (Figura 1).

Tabela 1. Teor de alumínio ( $\mathrm{Al})$; cobre $(\mathrm{Cu})$; ferro $(\mathrm{Fe})$ e fósforo $(\mathrm{P})$ na camada de $0-10 \mathrm{~cm}$, que recebeu as doses de pó de basalto, com e sem adubação química complementar.

\begin{tabular}{|c|c|c|c|c|}
\hline Adubação & $\mathrm{Al}$ & $\mathrm{Cu}$ & $\mathrm{Fe}$ & $\mathrm{P}$ \\
\hline & $\mathrm{mmol}_{\mathrm{c}} \mathrm{dm}^{-3}$ & - & $\mathrm{mg} \mathrm{dm}^{-3}$ & - \\
\hline Com & $0,00 \mathrm{~b}$ & $13,23 \mathrm{~b}$ & $39,58 \mathrm{~b}$ & $24,13 \mathrm{a}$ \\
\hline Sem & $0,705 \mathrm{a}$ & $13,81 \mathrm{a}$ & $43,66 \mathrm{a}$ & $14,09 \mathrm{~b}$ \\
\hline
\end{tabular}

Fonte: Tebar (2020).

As médias seguidas da mesma letra na coluna não diferem entre si pelo teste t a $5 \%$ de probabilidade. Portanto, observa-se que para estas variáveis as letras foram diferentes, demonstrando que houve diferença estatística. Apenas para a variável P, a média dos tratamentos com adubação foi maior do que sem adubação.

Com relação a variável P, esses resultados já eram esperados pela adição direta de fósforo (P), via adubação. Segundo Santos et al. (2008), a adição de fertilizantes fosfatados ocasiona acúmulo de P inorgânico com alta disponibilidade na superfície do solo, consequência da adição consecutiva de fertilizantes na camada superficial. Apesar das parcelas que não receberam adubação apresentarem menores teores de P, estes se encontram adequados de acordo com Sousa et al. (2016).

Isto possivelmente pode ser explicado pelo comportamento que as frações menos lábeis apresentam como fonte ou dreno de fósforo disponível. Segundo Santos et al. (2008), quando a quantidade de fósforo adicionada via fertilizantes é maior que a quantidade exportada pelo sistema, via absorção das plantas e perdas, a porção remanescente é estabilizada em formas de labilidade intermediária, que atuam como dreno do fósforo adicionado. Em contrapartida, quando a adição de fósforo não ocorre ou é inferior a quantidade necessária na exportação, as formas de $\mathrm{P}$ de labilidade intermediária atuam como fonte, mantendo os teores da solução do solo. Dessa forma, mesmo sem receber adubação, a média de P estava adequada, possivelmente pela atuação das formas de $\mathrm{P}$ de labilidade intermediária como fonte.

$\mathrm{O}$ solo das parcelas sem adubação química apresentou médias maiores de $\mathrm{Al}, \mathrm{Cu}$ e $\mathrm{Fe}$, em relação às parcelas com adubação. Possivelmente, devido a adubação e extração dos elementos pelas plantas. Segundo Gritti \& Roscoe (2017), os valores de $\mathrm{Cu}$ e Fe estão muito altos. As plantas das parcelas adubadas desenvolveram-se melhor em relação às plantas que não receberam adubação, assim a exigência nutricional das plantas sem adubação foi menor, absorvendo menos os elementos $\mathrm{Al}$, $\mathrm{Cu}$ e Fe, e consequentemente menor foi a extração do solo.

Com relação ao efeito residual do pó de basalto para a variável Fe (Figura 1), observa-se aumento linear dos valores em função das doses de pó de rocha. 
Figura 1. Valores de Fe no solo em função das doses de pó de rocha, em Mg.ha-1 ${ }^{-1}$ na cultura da soja.

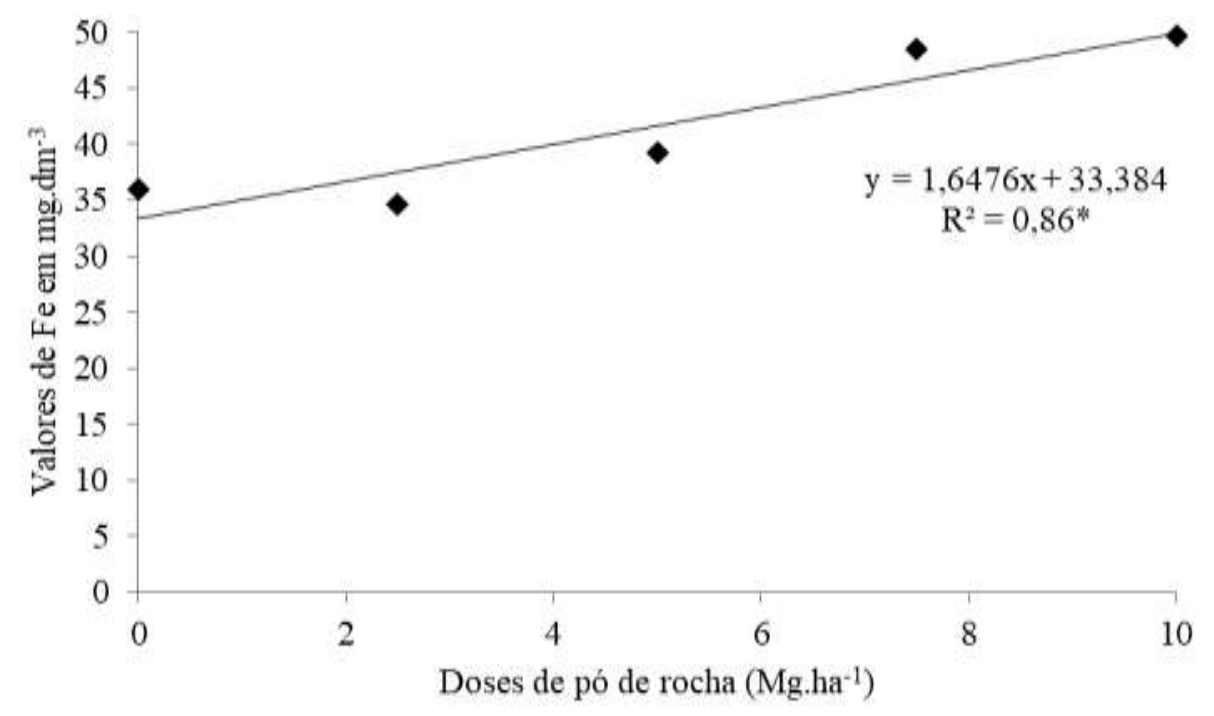

Fonte: Tebar (2020).

O símbolo “*” representa que $\mathrm{R}^{2}$ foi significativo a $5 \%$. Os valores de Fe se ajustaram ao modelo matemático linear, conforme as doses aumentaram, os teores de Fe também aumentaram. De acordo com Gritti e Roscoe (2017), os valores de Fe encontrados estão classificados como muito altos. Nunes (2012) explica que rochas máficas, como o basalto, apresentam teores elevados de micronutrientes, em destaque o ferro.

Dessa forma, devido à constituição do basalto ser rico neste elemento, a adição do pó de rocha ocasionou elevação nos teores de ferro no solo, sendo diretamente proporcional ao aumento da dose. Resultados semelhantes foram encontrados por Melo et al. (2012), em trabalho realizado com doses de basalto moído em um Latossolo Amarelo distrófico, os quais relataram que os teores de Fe aumentaram linearmente com as doses de pó de basalto. Pádua (2012) explica que isto é coerente quando se trata de Latossolos, pois são ricos em óxidos de ferro e também pelas altas concentrações deste elemento na composição da rocha testada.

Para os atributos químicos da camada de 10-20 cm, houve efeito isolado da adubação química para as variáveis P, Ca, $\mathrm{Cu}$ e Mn (Tabela 2) e efeito isolado do pó de rocha para pH em $\mathrm{H}_{2} \mathrm{O}$ e Mn (Figura 2 e 3, respectivamente).

Tabela 2. Teor de cálcio $(\mathrm{Ca})$; cobre $(\mathrm{Cu})$; ferro $(\mathrm{Fe})$ e fósforo $(\mathrm{P})$ em solo da camada de 10-20 cm, que recebeu as doses de pó de basalto, com e sem adubação química complementar.

\begin{tabular}{crrrr}
\hline Adubação & $\mathrm{Ca}$ & $\mathrm{Cu}$ & $\mathrm{Mn}$ & $\mathrm{P}$ \\
\hline $\mathrm{mmol}_{\mathrm{c}} \mathrm{dm}^{-3}$ & & $\mathrm{mg} \mathrm{dm}^{-3}$ & \\
\hline Com & $25,98 \mathrm{~b}$ & $13,52 \mathrm{~b}$ & $47,94 \mathrm{~b}$ & $9,00 \mathrm{a}$ \\
Sem & $29,21 \mathrm{a}$ & $14,09 \mathrm{a}$ & $58,24 \mathrm{a}$ & $6,60 \mathrm{~b}$ \\
\hline
\end{tabular}

Fonte: Tebar (2020).

As médias seguidas da mesma letra na coluna não diferem entre si pelo teste $\mathrm{t}$ a $5 \%$ de probabilidade. Portanto, observa-se que as letras foram diferentes, demonstrando que houve diferença estatística. Somente para a variável P, a média dos tratamentos com adubação química foi maior do que sem adubação.

Segundo Sousa et al. (2016), o valor de P para as parcelas com e sem adubação está alto. Para as parcelas sem adubação, o valor de $\mathrm{P}$ estar adequado pode ser explicado pelo comportamento que as frações menos lábeis apresentam como 
fonte ou dreno de fósforo disponível, como já discutido anteriormente. Para as parcelas com adubação, era esperado que estas apresentassem maiores valores de $\mathrm{P}$ devido a adição de fertilizante no sulco de semeadura. Para $\mathrm{Ca}, \mathrm{Cu}$ e $\mathrm{Mn}$ os teores foram maiores nas parcelas sem adubação complementar. Isto pode ser explicado devido a adubação e posteriormente extração de nutrientes pelas plantas. As plantas das parcelas adubadas desenvolveram mais que as sem adubação, assim a exigência nutricional das plantas sem adubação foi menor, absorvendo menos os elementos, verificando-se maiores teores destes no solo. Segundo Gritti e Roscoe (2017), os valores de Cu e Mn encontram-se altos e de Ca médio.

Com relação ao efeito isolado do pó de rocha para pH em $\mathrm{H}_{2} \mathrm{O}$ (Figura 2), os dados se ajustaram ao modelo quadrático.

Figura 2. Valores de $\mathrm{pH}$ em $\mathrm{H}_{2} \mathrm{O}$ em função das doses de pó de rocha basáltica, em $\mathrm{Mg}$.ha $^{-1}$, na cultura da soja.

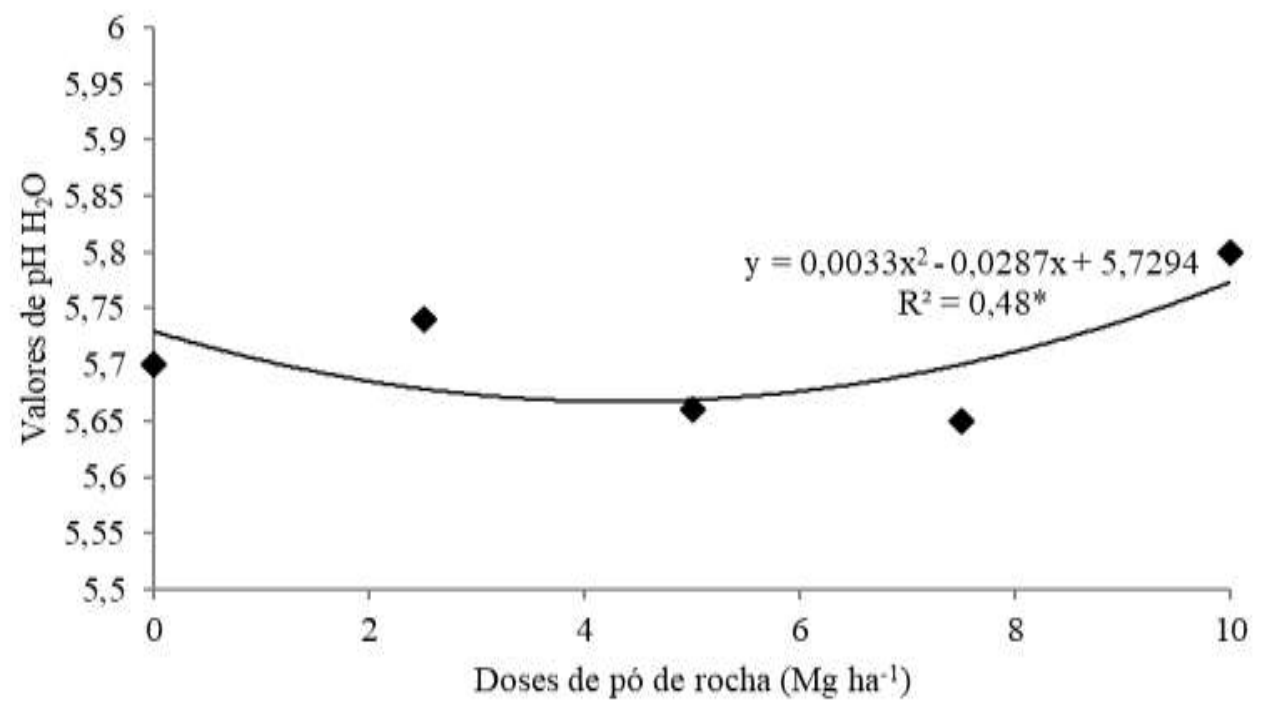

Fonte: Tebar (2020).

$\mathrm{O}$ símbolo “*” representa que $\mathrm{R}^{2}$ foi significativo a 5\%. Conforme as doses aumentaram, o valor de $\mathrm{pH}$ reduziu e depois aumentou, podendo-se calcular o ponto de mínimo da curva quadrática. O menor valor de $\mathrm{pH}$ obtido foi de 5,67 com a dose de 4,67 Mg.ha ${ }^{-1}$. O valor encontra-se adequado para o crescimento e desenvolvimento da cultura da soja, segundo Sousa e Lobato (1996).

Dessa forma, o pó de basalto influenciou no aumento do $\mathrm{pH}$, adequado ao desenvolvimento da cultura. Possivelmente, devido a capacidade do pó de rocha em atuar na melhoria das propriedades físico-químicas do solo, por meio da adição de partículas minerais. Segundo Silveira (2016), regiões tropicais que apresentam solos intemperizados com caráter distrófico, alumínico, ácrico, alítico e de pH ácido, condicionam um ambiente favorável para a dissolução de minerais silicatados dos remineralizadores. Em consonância, Theodoro (2000) explica que o uso de pó de rochas, principalmente as máficas, como o basalto, em solos tropicais, liberam cátions básicos que atuarão na reconstrução da fertilidade natural do solo.

Os valores de Mn no solo também foram influenciados pelas doses de basalto (Figura 3). 
Figura 3. Valores de Mn no solo em função das doses de pó de rocha basáltica, em Mg.ha-1, na cultura da soja.

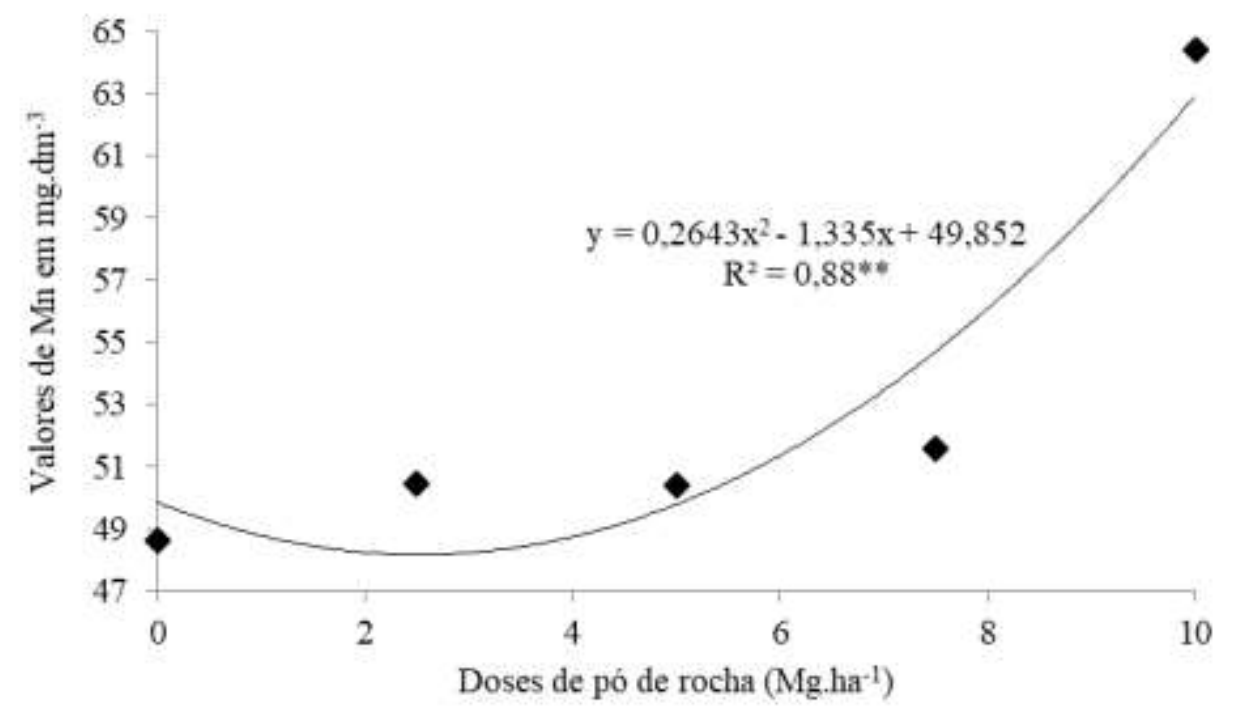

Fonte: Tebar (2020).

O símbolo “**” representa que $\mathrm{R}^{2}$ foi significativo a $1 \%$. Os dados se ajustaram ao modelo quadrático. Conforme as doses aumentaram, os teores de Mn reduziram e depois aumentaram, sendo possível calcular o ponto de mínimo da curva. Sendo assim, obteve-se o menor valor de Mn de 48,16 mg.dm ${ }^{-3}$ com a dose de 2,53 $\mathrm{Mg} \mathrm{ha}^{-1}$. Segundo Sousa e Lobato (1996), este valor é considerado alto, devendo-se atentar ao risco de toxicidade à cultura. Possivelmente, estava alto devido a própria constituição do pó de basalto.

A respeito da análise microbiológica do solo, esta foi realizada para verificar a influência do pó de rocha nos atributos microbiológicos do solo, os quais são: $\mathrm{qCO}_{2}$ e qMIC.

$\mathrm{O} \mathrm{qCO}_{2}$, segundo Ribeiro et al. (2015), representa a quantidade de carbono da respiração basal liberada por unidade de biomassa microbiana, o qual tende a ser maior em sistemas de manejos que promovem o rompimento dos macro e micro agregados, expondo a matéria orgânica à ação da atividade microbiana, aumentando a taxa de mineralização e liberação de $\mathrm{CO}_{2}$ para a atmosfera.

O qMIC, segundo Junior e Mendes (2007), é expresso pela razão carbono da biomassa microbiana do solo (CBMS) e o carbono orgânico total do solo (COT). O qMIC é uma forma de interpretar o acúmulo ou perda de C do solo, sendo $2 \%$ considerado o nível no qual há equilíbrio no sistema (Balota et al., 1998). No presente trabalho, o qMIC encontrado foi de $1,47 \%$.

Todavia, não houve interação entre as doses de pó de basalto e a adubação química complementar (p < 0,01), nem efeito isolado da adubação, nem do pó de rocha para as variáveis microbiológicas analisadas (Tabela 3).

Tabela 3. Resumo da análise de variância, valores do Teste F, para $\mathrm{qCO}_{2}$ e qMIC, da camada de 0-10 cm do solo.

\begin{tabular}{ccccc}
\hline \multirow{2}{*}{ Fator de variação } & Doses (D) & Adubação (A) & Média & C.V. (\%) \\
\hline $\mathrm{qCO}_{2}$ & $0,4152 \mathrm{~ns}$ & $0,6789 \mathrm{~ns}$ & 59,82 & 71,24 \\
qMIC & $0,8050 \mathrm{~ns}$ & $0,9583 \mathrm{~ns}$ & 1,47 & 32,67 \\
\hline
\end{tabular}

Fonte: Tebar (2020). 
Os símbolos “**”, “*”, “ns” representam significativo a 1\%, 5\% e não significativo, respectivamente. O coeficiente de variação (C.V \%), está muito alto, para o $\mathrm{qCO}_{2}$, e alto para o qMIC, demonstrando baixa precisão dos dados analisados.

Sobre a análise foliar, houve efeito significativo da adubação química complementar para as variáveis potássio (K), magnésio $(\mathrm{Mg})$ e cobre $(\mathrm{Cu})$ (Tabela 4), efeito isolado do pó de rocha para as variáveis $\mathrm{K}$, Ca e Mn (Figura 4, 5 e 6, respectivamente) e interação significativa entre as doses de pó de rocha e adubação química complementar para a variável fósforo (P) (Figura 7).

Tabela 4. Teor de potássio $(\mathrm{K})$, magnésio $(\mathrm{Mg})$ e cobre $(\mathrm{Cu})$ no tecido foliar da soja.

\begin{tabular}{|c|c|c|c|}
\hline \multirow{2}{*}{ Adubação } & $\mathrm{K}$ & $\mathrm{Mg}$ & $\mathrm{Cu}$ \\
\hline & \multicolumn{2}{|c|}{ g. $\mathrm{Kg}^{-1}$} & mg. $\mathrm{Kg}^{-1}$ \\
\hline Com & $20,02 \mathrm{a}$ & $3,48 \mathrm{~b}$ & 8,47 a \\
\hline Sem & $17,99 \mathrm{~b}$ & $3,66 \mathrm{a}$ & $7,65 \mathrm{~b}$ \\
\hline
\end{tabular}

Fonte: Tebar (2020).

As médias seguidas da mesma letra na coluna não diferem entre si pelo teste $\mathrm{t}$ a $5 \%$ de probabilidade. Portanto, observa-se que as letras foram diferentes, demonstrando que houve diferença estatística. Somente para a variável Mg, sem adubação química complementar obteve-se maior média de teores de $\mathrm{Mg}$ foliar.

A respeito do efeito isolado do pó de rocha, para a variável K, os dados se ajustaram ao modelo quadrático (Figura 4).

Figura 4. Teores de K no tecido foliar da soja, em função das doses de pó de basalto aplicadas ao solo.

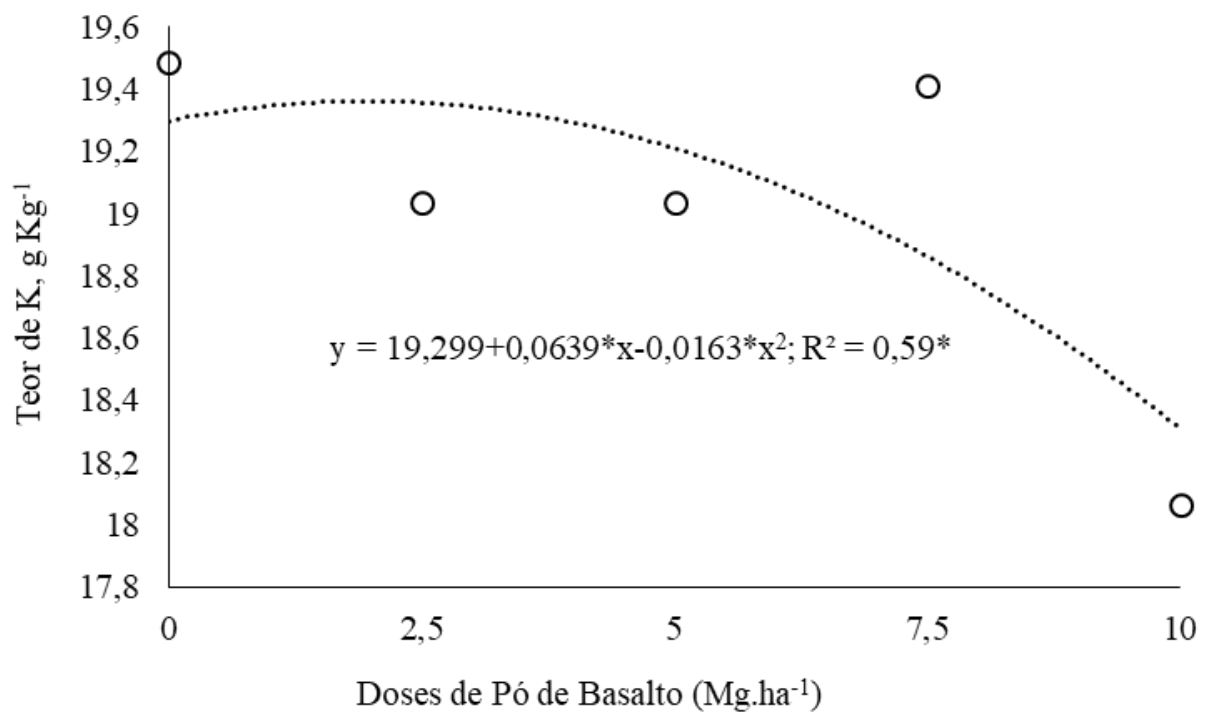

Fonte: Tebar (2020).

O símbolo “*” representa que $\mathrm{R}^{2}$ foi significativo a 5\%. Conforme as doses aumentaram, os teores de $\mathrm{K}$ reduziram, sendo possível encontrar o maior teor de $\mathrm{K}, 19,36 \mathrm{~g} \cdot \mathrm{Kg}^{-1}$, com a dose de 1,96 Mg ha-1 do pó de rocha.

Para a variável cálcio, os dados se ajustaram ao modelo quadrático, representados na Figura 5. 
Figura 5. Teores de Ca no tecido foliar da soja, em função das doses de pó de basalto aplicadas ao solo.

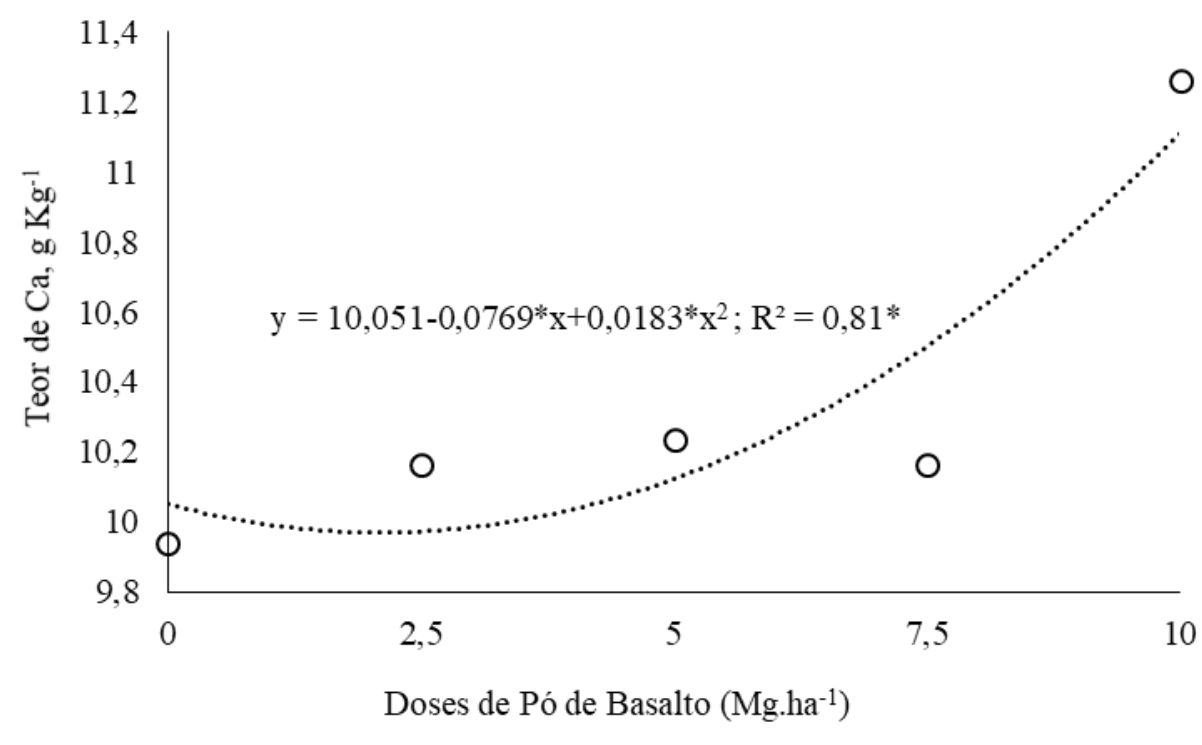

Fonte: Tebar (2020).

O símbolo “*” representa que $\mathrm{R}^{2}$ foi significativo a $5 \%$. Conforme as doses de basalto aumentaram, os teores de Ca demonstraram certo aumento, sendo possível calcular o menor teor, 9,97 g. $\mathrm{Kg}^{-1}$, com a dose de 2,10 Mgha-1 do pó de rocha.

Para a variável Mn, os dados também se ajustaram ao modelo matemático quadrático. (Figura 6).

Figura 6. Teores de Mn no tecido foliar da soja, em função das doses de pó de basalto aplicadas ao solo.

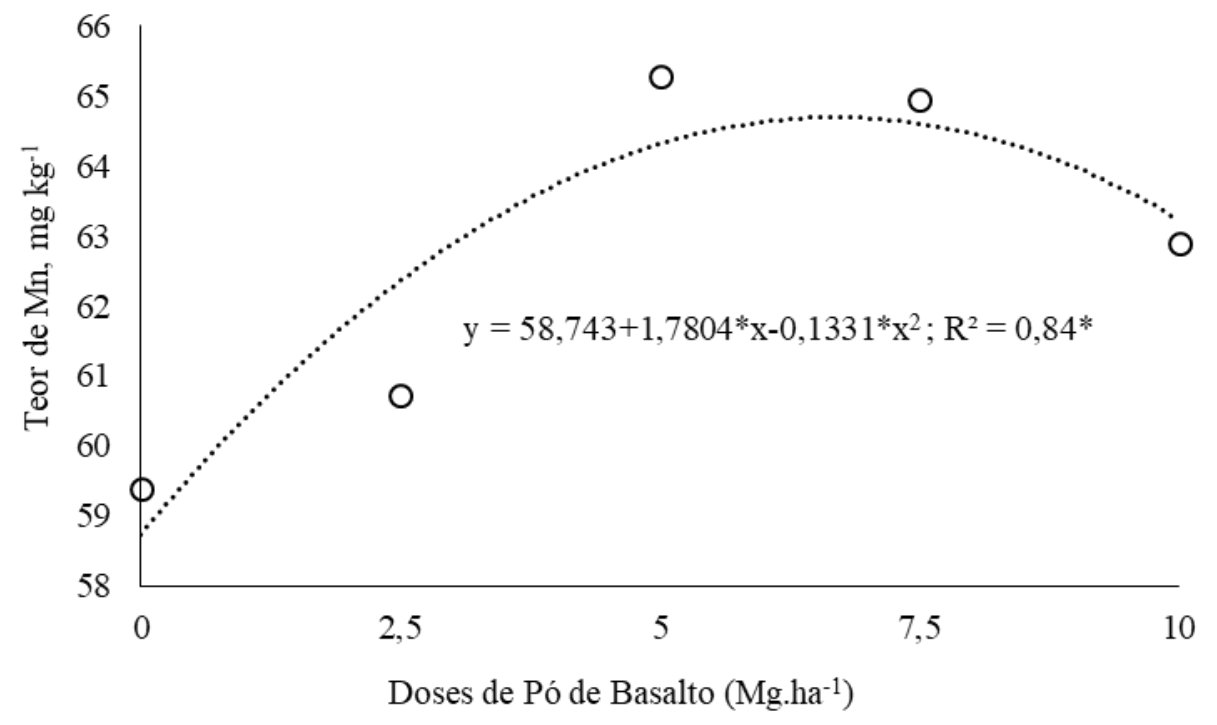

Fonte: Tebar (2020).

O símbolo “*” representa que $\mathrm{R}^{2}$ foi significativo a $5 \%$. Conforme as doses de basalto aumentaram, houve aumento dos teores de Mn e depois declínio. Obteve-se o máximo valor de Mn, 64,69 mg. $\mathrm{Kg}^{-1}$, com a dose de 6,42 Mg.ha ${ }^{-1}$ do pó de rocha.

Já para a variável P, houve interação significativa entre as doses de pó de basalto e adubação química complementar (Figura 7). 
Figura 7. Teores de P no tecido foliar da soja, em função das doses de pó de basalto aplicadas ao solo, com e sem adubação química complementar.

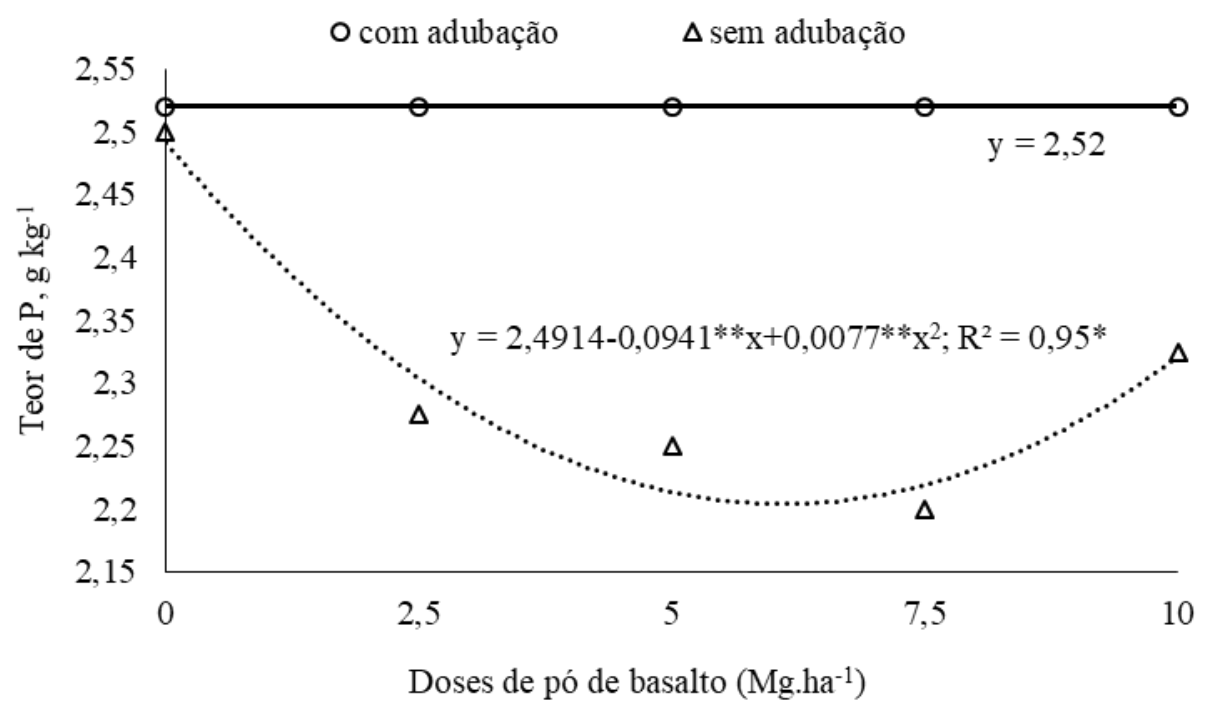

Fonte: Tebar (2020).

O símbolo “*” representa que $\mathrm{R}^{2}$ foi significativo a 5\%. A partir da Figura 7, verifica-se que com adubação química complementar não houve ajuste dos dados aos modelos matemáticos, utilizando-se a média de 2,52 g.Kg-1 de P. Enquanto que sem adubação, os dados se ajustaram ao modelo quadrático, obtendo-se o menor teor de P (2,204 g.Kg-1) com a dose de 6,11 Mg.ha- ${ }^{-1}$ de basalto. Sendo assim, maiores teores de P (2,25 kg.ha-1) foram encontradas nas parcelas que receberam adubação química, independente das doses de pó de basalto.

De maneira geral, os teores de K, P, Ca, Mg, e Mn foliares estão na faixa adequada segundo Sousa \& Lobato (2004), com exceção do teor de $\mathrm{Cu}$, que ficou abaixo do adequado para a cultura da soja. Segundo os autores, nem sempre há correlação entre os teores dos nutrientes encontrados na análise de solo e os encontrados no tecido foliar, pois na análise de solo utilizam-se soluções extratoras que podem superestimar um nutriente no solo e não quer dizer que este será utilizado pela planta, enquanto que a análise foliar demonstra os teores totais dos nutrientes absorvidos pela cultura. Além disso, os autores ressaltam que os nutrientes presentes na análise foliar dependem de vários fatores além da disponibilidade deste no solo, como umidade e acidez do solo, bem como desenvolvimento do sistema radicular, atividade microbiana, tipo fertilizante utilizado, condições climáticas, antagonismo e sinergia entre elementos e mineralização da matéria orgânica.

\section{Conclusão}

A adubação química influenciou os teores dos elementos P, Al, Cu e Fe na camada de 0-10 cm. Nesta, houve redução de $\mathrm{Al}, \mathrm{Cu}, \mathrm{Fe}$ e aumento de $\mathrm{P}$ nas parcelas que receberam adubação. Na camada de 10-20 cm, a adubação química influenciou os teores de $\mathrm{Ca}, \mathrm{Cu}, \mathrm{Mn}$ e $\mathrm{P}$. Nesta, houve redução de $\mathrm{Ca}, \mathrm{Cu}$ e $\mathrm{Mn}$ e aumento de $\mathrm{P}$ nas parcelas que receberam adubação.

O efeito residual da aplicação do pó de basalto ocasionou aumento nos teores de Fe na camada de $0-10 \mathrm{~cm}$ e do pH em água e de Mn na camada de 10-20 cm.

O residual do pó de basalto não promoveu alteração no quociente metabólico e microbiano do solo.

Diante do exposto, aconselha-se que os trabalhos desenvolvidos na área da rochagem avaliem os atributos físicos, como a porosidade do solo, e os microbiológicos, como as enzimas microbianas e a formação de micorrizas, pois estes atributos podem influenciar a solubilização do pó de rocha, afetando, consequentemente, os atributos químicos do solo. Além 
disso, deve-se realizar mais estudos com a rochagem em outros sistemas de cultivo, principalmente no sistema plantio direto (para grãos) e nos sistemas agroflorestais, para verificar a influência da cobertura do solo, rotação de culturas e consórcio de plantas na eficiência do pó de rocha ao disponibilizar nutrientes, melhorar a porosidade e incrementar a microbiologia do solo.

\section{Agradecimentos}

Agradecimentos ao Conselho Nacional de Desenvolvimento Científico e Tecnológico (CNPq) pela bolsa de iniciação científica concedida à aluna Mariana Manzato Tebar; à UFGD pela infraestrutura e oportunidade de realizar pesquisa científica na graduação; aos trabalhadores terceirizados que sempre auxiliam nos experimentos da Fazenda Experimental de Ciências Agrárias (FAECA) e a orientadora Alessandra Mayumi Tokura Alovisi por todos os ensinamentos prestados.

\section{Referências}

Anderson, T. H. \& Domsch, K. H. (1990). Application of ecophysiological quotients ( $q$ CO ${ }_{2}$ and qD) on microbial biomasses from soils of different cropping histories. Soil Biology and Biochemistry, 22, 251-255.

Brasil (2013). Lei n ${ }^{\circ}$ 12.890, de 10 de dezembro de 2013. Remineralizadores como insumo à agricultura. Diário Oficial da União: seção 1.

Brito, R. S., Batista, J. F., Moreira, J. G. V., Moraes, K. N. O., \& Silva, S. (2019) O. Rochagem na agricultura: importância e vantagens para adubação complementar. South American Journal of basic education, technical and technological, 6(1), 528-540.

Gritti, D. C. \& Roscoe, R. (2017). Manejo e Fertilidade do Solo para a cultura da Soja: Fundação MS. Tecnologia e Produção: Soja.

Jenkinson, D. S. \& Powlson, D. S. (1976) The effects of biocidal treatments on metabolism in soil-I. Fumigation with chloroform. Soil Biology and Biochemistry. 8, 167-177.

Nunes, J. M. G. (2012). Caracterização de resíduos e produtos da britagem de rochas basálticas e avaliação da aplicação na rochagem. Dissertação (Mestrado de avaliação de impactos ambientais em mineração) - Centro Universitário La Salle, Canoas.

Padua, E. J. Rochagem como adubação complementar para culturas oleaginosas. 92 p. Dissertação (Mestrado em Fertilidade do solo e nutrição de plantas) Universidade Federal de Lavras.

Santos, D. R, Gatiboni, L. C., \& Kaminski, J. (2008) Fatores que afetam a disponibilidade do fósforo e o manejo da adubação fosfatada em solos sob sistema plantio direto. Revista Ciência Rural, Santa Maria, RS, 38(2), 576-586.

Sousa, D. M. G. \& Lobato, E. (1996). Correção do solo e adubação da cultura da soja. Embrapa Circular Técnica $\mathrm{n}^{\circ} 33$.

Sousa, G., Martinhão, D., Nunes, R. S., Rein, T. A., \& Junior, J. D. G. S. (2016). Manejo da adubação fosfatada para culturas anuais do cerrado. Embrapa Circular Técnica 33.

Theodoro, S. H. A fertilização da terra pela terra: uma alternativa para a sustentabilidade do pequeno produtor. Tese (Centro de desenvolvimento sustentável) - Universidade de Brasília.

Theodoro, S. H. \& Leonardos, O. H. (2011). Rochagem: uma questão de soberania nacional. Anais XIII Congresso Brasileiro de Geoquímica, Gramado, RS.

Theodoro, S. H., Leonardos, O. H., Rgeo, K. G., Medeiros, F. P., Talini, N. L., Santos, F., \& Oliveira, N. (2013). Efeito do uso da técnica de rochagem associada à adubação orgânica em solos tropicais. Anais do II Congresso Brasileiro de Rochagem, Poços de Caldas, MG, 32-41.

Vance, E. D., Brookes, P. C., \& Jenkinson, D. S. (1987). Na extraction method for measuring soil microbial biomass-C. Soil Biology \& Biochemistry, 19(6), 703-707.

Melo, F. V., Uchoa, P. C. S., Dias, O. F., \& Barbosa, F. G. (2012). Doses de basalto moído nas propriedades químicas de um Latossolo Amarelo distrófico da savana de Roraima. Acta Amazonica, 42(4), 471-476.

Malavolta, E., Vitti, G. C., \& Oliveira, S. A. de. (1997). Avaliação do estado nutricional da plantas: Princípios e aplicações. Piracicaba: Potafos, 115-230.

Costa, J.A. \& Marchezan, E. (1982). Características dos estádios de desenvolvimento da soja. Campinas: Fundação Cargill, 30p.

Silveira, R. T. G. (2016). Uso de rochagem pela mistura de pó de basalto e rocha fosfatada como fertilizante natural de solos tropicais lixiviados. Dissertação (Mestrado em Geociências) - Universidade de Brasília- Instituto de Geociências, Brasília, DF.

Ribeiro, I. S., Novak, E., Carvalho, L. A., Mercante, F. M., Brumatti, A. A., \& Zacarias, R. A. (2015). Monitoramento dos atributos microbiológicos do solo em diferentes usos. XXXV Congresso brasileiro de Ciência do Solo, Natal, RN.

Junior, F. B. R. \& Mendes, I. C. (2007). Biomassa microbiana do solo. Embrapa Documentos 205, Planaltina, DF.

Balota, E. L., Colozzi-Filho, A., Andrade, D. S., \& Hungria, M. (1998). Biomassa microbiana e sua atividade em solos sob diferentes sistemas de preparo e sucessão de culturas. Revista Brasileira de Ciências do Solo, 22, 641-649.

Sousa, D. M. G. \& Lobato, E. (2004). Cerrado Correção do solo e Adubação. Embrapa, 245-254. 